\title{
Applying Wenger's communities of practice theory to placement learning
}

\section{Dawn Morley}

Etienne Wenger's community of practice theory (1998) evolved from Wenger's (1998) ethnographic research of medical claims processors working collaboratively as part of a unique group.

"Communities of practice are groups of people who share a concern, a set of problems, or a passion about a topic, and who deepen their knowledge and expertise in this area by interacting on an ongoing basis" (Wenger, McDermott and Snyder 2002, p.4)

The community of practice theory has been firmly established in business as part of knowledge exchange processes (Wenger et al 2002, Choi 2006) and has also informed the evolvement of student nurse "Dedicated Education Units" in Australia and the USA (Ranse and Grealish 2007, Moscato, Miller, Logsdon, Weinberg and Chorpenning 2007, Grealish and Ranse 2009, Grealish, Bail and Ranse 2010). Its impact on practice learning in the UK has however been limited despite the applicability of Wenger's social learning theory. Grealish and Ranse (2009, p.81) noted that "the messiness of busy workplaces as social hives of activity and influence is rendered invisible in many cognitive learning theories" suggesting that a greater recognition of the richness of the social learning environment, and the collaborative learning that results, would better optimise the many planned and unplanned opportunities for learning in this setting.

Wenger's earlier collaborative work challenged the traditional emphasis on learning as an individual activity rather than as a group or social process (Lave and Wenger (1991). The community of practice theory introduced the idea that the sharing of practice in a like minded but unique professional group advanced both the learning and professional identity of group members. The deep socialisation that resulted involved both "old timers" (seasoned practitioners) and "newcomers" whose identities and practice could be further developed by collaborative participation in the community.

Staff nurses acknowledged this process with student nurses in a Dedicated Education Unit where they felt their own knowledge was enhanced by the students they supervised 
(Grealish, Bail and Ranse 2010). This in particular shows the power of effective collaborative learning when inexperience challenges accepted cultural norms on placement leading to "the process of remaking and possibly transforming culturally derived practices" (Billett 2007 , p. 59). Wenger (1998) argued that the contribution of novices to the overall ethos of a community of practice can be significant to the generation of new knowledge and collaborative ways of working.

With its emphasis on an overarching culture of professional development Spouse (1998) saw many parallels between the community of practice theory and the development of the student nurse. She viewed the mentor as an essential sponsor to a student as a newcomer to a community that fostered the type of self worth and professional identity identified by Wenger (1998).

Sharing practice allows the opportunity for a particular culture to continue within the next generation and Wenger (1998) visualised learning as a longitudinal journey where development rested not only in the present but also with the identification of future goals and aspirations. Working with more experienced colleagues was significant for new comers for senior staff were "living testimonies to what is possible, expected, desirable" (Wenger 1998, p.156). The more experienced colleague embodied the history and ethos of the community of practice and could have a significant impact on the professional socialisation and identity formation of the newcomer.

The importance of role models for student nurses' appreciation of "emotional labour and the job of nursing" (Smith and Gray 2001, p. 233) has always been apparent although Grealish and Ranse (2009) criticised preceptorship (the equivalent of mentorship in the UK) as promoting clinical supervision at the level of individual student activity and missing the important collaborative learning that occurred in student nurses' clinical placements. In the UK the significant contribution of the health care assistant (Hassan, McKenna and Keeney 2013a, 2013b), patient (Webster, Goodhand, Haith and Unwin 2012; Robichaud, East, Beard and Morra 2012) and peer students (Aston and Molassiotis 2003, Sprengel and Job 2004) to students' practice learning remains relatively hidden but has a significant effect on the development of the student nurse (Morley 2015). 
By working together in practice, checking and negotiating the meaning of what they are doing together, Wenger identified (1998) individuals in a community of practice undertook mutual engagement with each other and practice theory arose collaboratively. Joint enterprise resulted when this process was successful. It created local ownership and response and fostered "regulations of mutual accountability that become an integral part of practice" (Wenger 1998, p.78). The shared repertoire of the community of practice created elements of commonality, such as key documentation and professional language, which become the tools with which to negotiate and renegotiate practice. The three aspects of mutual engagement, joint enterprise and shared repertoire were inextricably linked. For those studies that have endeavoured to apply community of practice criteria to clinical placement learning (Davis 2006; Thrysoe et al 2010) students were more participative in an enabling environment where a permissive consultative style of supervision existed.

Wenger identified simply strategies to counteract barriers to non participation of newcomers that many students experience (Morley 2015). Wenger (1998) argued that the potentially vulnerable nature of participation can be strengthened by reification where, for example, formal processes can make learning more explicit for the student. On placement, students for example, reflecting on their learning goals and outcomes through their practice portfolios to gain a greater appreciation of their professional development.

Wenger (1998) suggested the use of imagination and alignment to strengthen engagement. The strategy of imagination encourages students to look at alternatives outside the immediate context of practice and encourages them to think more broadly and be more critical of their practice. Alignment allows students "to connect their local efforts to broader styles and discourses in ways that allow learners to invest their energy in them" (Wenger 1998, p186) so practices in placements become more significant once aligned to, for example, discussion on professional bodies or government policy. The workings and idiosyncrasies of a community of practice presents challenges to being effective as a learning community. The right combination of participation, imagination and alignment can allow a multiplicity of ways to counteract the chasm that may exist between participation and non participation of students on placement. 
Wenger (1998) stressed that homogeneity was not key to a community of practice but openness to learning, from the diversity of other community members, had the potential to capitalise on complementary contributions of knowledge and experience. The strong bonds that may enhance the functioning of a community of practice may, however, create barriers for the newcomer trying to enter the community. Although communities of practice can be transformative Wenger (1998) warned against the entrapment of a particular way of working that can "conversely ... hold (participants) hostages to that experience" (Wenger 1998, p85.). There are startling examples of student nurses being unable to engage in working and learning in the practice setting due to poor mentor support (Thyrsoe at al 2010, Bradbury- Jones et al 2011, Morley 2015) or horizontal and vertical bullying from both trained and untrained staff (Longo 2007, Hoel, Giga and Davison 2007, Thomas and Burk 2009, Morley 2015). Roberts (2006) argued, that over time, a community of practice may develop a filter to the knowledge that it negotiates and, as a consequence, risks stagnation and socialisation to only one particular way of thinking. Student nurses who feel restricted in the practice learning environment due to a lack of belongingness (Levett-Jones and Lathlean 2008) are not encouraged to pursue critical enquiry of their practice learning and subsequently will learn in a routine driven community of practice that Wenger (1998) warned against.

Student learning, like all learning within a community of practice, is a dynamic process that needs nurturing. Wenger (1998) recognised some of the possible shortcomings of group dynamics within a community of practice that are particularly recognisable within nursing. Most significantly "when old timers and newcomers are engaged in separate practices, they lose the benefit of their interaction"(Wenger 1998, p275). Limiting the amount of time between student nurses and their mentors limits the ability of student nurses to access the wide reality of professional work that students' aspire to. By remaining in close proximity to a more experienced professional, student nurses are in the unique position to join the many fragmented aspects of the qualified nurses' role into a whole that students can appreciate and learn from even in the early stages of their professional development (Morley 2015). Spouse (2001 pp 519-520), in a longitudinal study examining the case studies of eight pre registration nurses, found that "if [the student] had been left to wander around the ward talking to patients, or had been given mundane activities that had kept her busy and out of 
the mentor's way, she would have missed out on learning the artistry and the science of caring ...that her mentor could teach her" (Spouse 2001, p.23).

Through engagement student nurses can therefore adopt the identity of student nurses through the lived experience of practice. This role can be augmented through the interaction with more senior colleagues, which exposes students to trajectories of possible future professional identities and practice. Furthermore opportunities for alignment and imagination, carefully woven with the experience of participation, can extend students' identities beyond the boundaries of immediate engagement.

Learning alters who students are and the way students practice so is central to the creation of a professional identity. As well as the knowledge created at the core of a community of practice through full membership, Wenger (1998) believes that knowledge at the peripheries can also be innovative and reflective as they may not be so strongly influenced into the socialisation of the community of practice. The periphery of a community of practice may allow a participant, whether newcomer or old timer, a window into the practice of the community of practice without the responsibilities of full membership. Fuller and Unwin (2003) found that "expansive", as opposed to "restrictive", apprenticeships promoted stronger and richer learning settings. These were characterised by apprentices working across communities of practice where they were exposed to a greater range of experience and learning in their practice which also extended to their expectations for future career opportunities.

In summary Wenger (1998) argued that a community of practice offered newcomers the experience of professional competence and the environment in which to practice and strengthen their professional identity. As well as the acquisition of accepted knowledge new knowledge was also created from the ability to question known practice and through mutual engagement, joint enterprise and a shared repertoire negotiation built the possibilities of new practice.

Morris (2012), in participant observation and informal interviews of UK medical students' attachments to their clinical firms, highlighted that the individual dimension in the relationship between the medical student and their community of practice learning was 
significant. The personal ability and motivation of the individual student to seek out learning opportunities was as significant to the learning process as the community of practice's ability to successfully foster and support it. Billett (2011) cautioned against a purely socio constructivist learning approach that did not recognise an individual students' previous cognitive experience or their usual methods of learning in a given setting. What Billett (2011) terms workplace affordances, such as the effect of the mentor on learning (Gray and Smith 2000, Spouse 2001, Myall et al 2008) or student nurses' previous care experience working as health care assistants (Holland 1999, Morley 2015), can significantly alter this balance.

Wenger has been criticised for the lack of recognition of the individual agency of the learner within communities of practice and for a positivity that obscures the political (Roberts 2006) and power (Fox 2000) dimensions of community participation that may affect practice engagement. Wenger does, however, provide a thoughtful learning model for practice where student engagement, crucial to learning, is scrutinised and alternative strategies offered. Much of the richness of practice learning can occur randomly and risks to be hidden against the business of work practice (Benner 1984; Eraut 2000, 2004). Wenger provides a recognisable learning structure that is applicable to clinical learning where the development of current and future professional development of students is paramount.

Aston, L. and Molassiotis, A., 2003. Supervising and supporting student nurses in clinical placements: the peer support initiative. Nurse Education Today, 23 (3), 202-210.

Benner, P., 1984. From Novice to Expert. Excellence and Power in Clinical Nursing Practice. California: Addison-Wesley Publishing Company.

Billett, S., 2007. Including the missing object: placing the personal within the community. In: Hughes, J., Jewson, N. and Unwin, L., eds. Communities of Practice. Critical perspectives. London and New York: Routledge, 55-67. 
Billett, S., 2011. Subjectivity, Self and Personal Agency in Learning Through and for Work. In: Malloch, M., Cairns, L., Evans, K. and O'Connor, B., eds. The Sage Handbook of Workplace Learning. London/California/New Delhi/Singapore: Sage Publications Ltd, 60-73.

Bradbury- Jones, C., Sambrook, S. and Irvine, F., 2011. Empowerment and being valued: A phenomenological study of nursing students' experience of clinical practice. Nurse Education Today, 31, 368-372.

Choi, M., 2006. Communities of practice: an alternative learning model for knowledge creation. British Journal of Educational Technology, 37 (1), 143-146.

Eraut, M., 2000. Non-formal learning and tacit knowledge in professional work. British Journal of Educational Psychology, 70, 113-136.

Eraut, M., 2004. Informal learning in the workplace. Studies in Continuing Education, 26 (2), 247-273.

Fox, S., 2000. Communities of practice, Foucault and Actor-Network Theory. Journal of Management Studies, 37 (6), 853-867.

Fuller, A. and Unwin, L., 2003. Learning as Apprentices in the Contemporary UK Workplace: creating and managing expansive and restrictive participation. Journal of Education \& Work, $16(4), 407-426$.

Grealish, L., Bail, K. and Ranse, K., 2010. 'Investing in the future': residential aged care staff experiences of working with nursing students in a 'community of practice'. Journal of Clinical Nursing, 19 (15-16), 2291-2299.

Grealish, L. and Ranse, K., 2009. An exploratory study of first year nursing students' learning in the clinical workplace. Contemporary Nurse, 33 (1), 80-92.

Hasson, F., McKenna, H. P. and Keeney, S., 2013a. Delegating and supervising unregistered professionals: the student nurse experience. Nurse Education Today, 33 (3), 229-235. 
Hasson, F., McKenna, H. P. and Keeney, S., 2013b. Perceptions of the unregistered healthcare worker's role in pre-registration student nurses' clinical training. Journal of Advanced Nursing, 69 (7), 1618-1629.

Hoel, H., Giga, S. I. and Davidson, M. J., 2007. Expectations and realities of student nurses' experiences of negative behaviour and bullying in clinical placement and the influences of socialization processes. Health Services Management Research: An Official Journal Of The Association Of University Programs In Health Administration / HSMC, AUPHA, 20 (4), 270278.

Holland, K., 1999. A journey to becoming: the student nurse in transition. Journal of Advanced Nursing, 29 (1), 229-236.

Lave, J. and Wenger, E., 1991. Situated Learning. Legitimate peripheral participation. New York: Cambridge University Press.

Levett-Jones, T. and Lathlean, J., 2008. Belongingness: A prerequisite for nursing students' clinical learning. Nurse Education Today, 8, 103-111.

Longo, J., 2007. Horizontal violence among nursing students. Archives of Psychiatric Nursing, 21, 177-178.

Morley, D. A., 2015. A grounded theory study exploring first year student nurses' learning in practice. (Doctor in Professional Practice). Bournemouth.

Morris, C., 2012. Reimagining "the firm": clinical placements as time spent in communities of practice. In: Cook, V., Daly, C. and Newman, M., eds. Work-based Learning in Clinical Settings. London and New York: Radcliffe Publishing, 11-25.

Moscato, S. R., Miller, J., Logsdon, K., Weinberg, S. and Chorpenning, L., 2007. Dedicated education unit: An innovative clinical partner education model. Nursing Outlook, 55, 31-37. Myall, M., Levett-Jones, T. and Lathlean, J., 2008. Mentorship in contemporary practice: the experiences of nursing students and practice mentors. Journal of Clinical Nursing, 17, 18341842. 
Ranse, K. and Grealish, L., 2007. Nursing students' perceptions of learning in the clinical setting of the Dedicated Education Unit. Journal of Advanced Nursing, 58 (2), 171-179.

Roberts, J., 2006. Limits to communities of practice. Journal of Management Studies, 43 (3), 623-639.

Robichaud, P., East, J., Beard, L. and Morra, D., 2012. Let the patient teach: patient feedback will help prepare medical students for the changing healthcare world. Medical Teacher, 34 (3), 256-256.

Smith, P. and Gray, B., 2001. Reassessing the concept of emotional labour in student nurse education: role of link lecturers and mentors in a time of change. Nurse Education Today, $21,230-237$.

Spouse, J., 1998. Learning to nurse through legitimate peripheral participation. Nurse Education Today, 18, 345-351.

Spouse, J., 2001. Bridging theory and practice in the supervisory relationship: a sociocultural perspective. Journal of Advanced Nursing, 33 (4), 512-530.

Sprengel, A. D. and Job, L., 2004. Reducing student anxiety by using clinical peer mentoring with beginning nursing students. Nurse educator, 29 (6), 245-250.

Thomas, S. P. and Burk, R., 2009. Junior nursing students' experience of vertical violence during clinical rotations. Nursing Outlook, 57, 226-231.

Thrysoe, L., Hounsgaard, L., Bonderup Dohn, N. and Wagner, L., 2010. Participating in a community of practice as a prerequisite for becoming a nurse - Trajectories as final year nursing students. Nurse Education in Practice, 10, 361-366.

Webster, B. J., Goodhand, K., Haith, M. and Unwin, R., 2012. The development of service users in the provision of verbal feedback to student nurses in a clinical simulation environment. Nurse Education Today, 32 (2), 133-138.

Wenger, E., 1998. Communities of Practice. Learning, Meaning and Identity. New York: Cambridge University Press. 
Wenger, E., McDermott, R. and Snyder, W., 2002. Cultivating communities of practice : a guide to managing knowledge. Boston, Mass. London: Harvard Business School; McGrawHill distributor. 